\title{
Evaluation of the Cytotoxicity of Cholesterol Oxides in Human Colon Cancer Caco-2 Cells
}

\author{
Antonio Alfonso-García, Antonio Cilla*, Reyes Barberá, Amparo Alegría \\ Nutrition and Food Chemistry, Faculty of Pharmacy, University of Valencia, Spain \\ *Corresponding author: antonio.cilla@uv.es
}

Copyright $@ 2014$ Horizon Research Publishing All rights reserved.

\begin{abstract}
The content of cholesterol oxides (COPs) in foods varies between 0.1 and $294.3 \mathrm{mg} / \mathrm{g}$. These oxides are formed by auto-oxidative enzymatic processes promoted by the heat treatment of food and/or to exposition of them to the presence of oxygen and sunlight during storage. Their importance is that they are associated with pathological processes like apoptosis, dyslipidemia and pro-oxidative states, among others. The objective was to evaluate the cytotoxicity, by means MTT assay, of 7-keto cholesterol (7KC), cholestane-triol (Triol), $\alpha$-epoxy cholesterol $(\alpha$-epoxy $\quad \mathrm{C}), \quad \beta$-epoxy cholesterol $(\beta$-epoxy $C) \quad$ in differentiated Caco-2 cells at $120 \mu \mathrm{M}$ for 24,48 and $72 \mathrm{~h}$.Triol was the most cytotoxic COP, with a percentage of cell viability among 3.2 to 3.4 at all times studied. The $\beta$-epoxy $\mathrm{C}$ and $7 \mathrm{KC}$ showed similar percentages from 65.4 to 6.9 and 67.4 to 6.5 , respectively. The $\alpha$-epoxy $\mathrm{C}$ was the least cytotoxic ( 83.3 to $48.7 \%$ of cell viability).COPs in the study conditions, showed a cytotoxic effect on Caco-2 cells due to disruption of the integrity of mitochondrial function, being the most toxic compound the triol.
\end{abstract}

Keywords Cholesterol Oxides, Cytotoxicity, Caco-2 Cells

\section{Introduction}

Cholesterol oxidation products (COPs) are a family of compounds with different biological activities[1].In mammals, the COPs are derived from the diet or from the enzymatic oxidation of cholesterol produced in the tissues. The heat treatment of food (pasteurization, sterilization, etc.) or prolonged storage under an oxidizing atmosphere and/or in the presence of sunlight can significantly increase the concentration of these compounds in food[2].

After oral ingestion, the intestinal epithelium is the first physiological barrier for absorption. COPs are more rapidly absorbed and in more percentage than cholesterol, following then similar metabolism to cholesterol.Once in the bloodstream, they are rapidly taken up by the tissues. COPs toxicity varies and includes damage to the smooth muscle cells, endothelial cells and fibroblasts, and many others[3-5]. The toxic effects are attributed to the changes in permeability, membrane fluidity, membrane enzyme activity, modulation of intracellular calcium and inhibition of HMG-CoA reductase enzyme which regulates cholesterol synthesis[1,3-7], causing fibrosis processes, apoptosis and inflammation by inducing pro-oxidative state[8-10]. The COPS have demonstrated its involvement in the expression of molecules such as intercellular adhesion-1 (ICAM-1), adhesion molecule-1 (VCAM-1) and E-selectin[11], and proinflammatory cytokines such as interleukin-8 in vascular cells (IL-8)[12].

All these effects of COPs on a cellular level may translate into a systemic degenerative effects found in various organs and systems such as atherosclerosis, neurodegeneration (Alzheimer), renal failure and diabetes mellitus, among others[10,13].

In previous works, other authors tested different COPs (individually or mixed) on Caco-2 cells at concentrations comparable to the present work[14], evaluating additional parameters such as mitochondrial membrane potential, cell cycle progression, expression of the activity of caspases 3 and 7 and relative content of RNA[14-17]. In all cases cytotoxicity on Caco-2 cells was evident, which agrees with the results obtained in our study. However, in our study, longer exposure to the COPs was performed (until $72 \mathrm{~h}$ ) to find out how the viability was affected considering time and each individual COP.

Thus, based on this background, the objective of this study was to evaluate the individual cytotoxicity of several of the major oxysterols found in the $\operatorname{diet}[15]$ : 7-keto-cholesterol (7KC), cholestane-triol (triol), $\alpha$-epoxy-cholesterol ( $\alpha$-epoxy $\mathrm{C})$, and $\beta$-epoxy-cholesterol ( $\beta$-epoxy $\mathrm{C}$ ), at the highest concentration found in literature $(120 \mu \mathrm{M})[14]$ in differentiated Caco-2 cells, a validated model of intestinal epithelium, as a target organ that early encounters COPs after oral intake.

\section{Methods}




\subsection{Reagents and Media}

Dulbecco's Modified Eagle Medium (DMEM + GlutaMAX'M ${ }^{\mathrm{TM}}$, glucose, fetal bovine serum, nonessential amino acids, HEPES, antibiotic solution (penicillin-streptomycin), fungizone, phosphate buffered saline (PBS) and trypsin-EDTA $(2,5 \mathrm{~g} / \mathrm{L}$ trypsin and $0.2 \mathrm{~g} / \mathrm{L}$ of EDTA) were purchased from Gibco (Scotland, UK). 99.9\% ethanol. 7-keto-cholesterol (7KC), cholestane-triol (Triol), $\alpha$-epoxy-cholesterol ( $\alpha$-epoxy $\mathrm{C}$ ), and $\beta$-epoxy-cholesterol $(\beta$-epoxy $C)$ were from Steraloids (Newport, RI, USA), 3-[4, 5-dimethylthiazol-2-yl]-2,3-diphenyltetrazolium bromide (MTT) was obtained from Sigma Chemical Co. (St. Louis, MO, USA).

\subsection{Caco-2 Cells}

The differentiated cell cultures were used 5 days post-seeding[18]. Preliminary experiments showed that a 5-7 day time of incubation was required for Caco-2 cells to undergo differentiation[14].The cells of human colon adenocarcinoma (Caco-2) were purchased from the European Collection of Cell Cultures (ECACC86010202, Salisbury, UK) and used at passage 75 . They were cultured in $75 \mathrm{~cm}^{2}$ flasks in DMEM + GlutaMAX ${ }^{\mathrm{TM}}$ containing $1 \mathrm{~g} / \mathrm{L}$ glucose and supplemented with $10 \%(\mathrm{v} / \mathrm{v})$ fetal bovine serum, $1 \%(\mathrm{v} / \mathrm{v})$ nonessential amino acids, $1 \%(\mathrm{v} / \mathrm{v})$ of HEPES, $1 \%$ $(\mathrm{v} / \mathrm{v})$ antibiotic solution (penicillin-streptomycin) and $0.2 \%$ (v/v) fungizone. The cells were incubated at $37^{\circ} \mathrm{C}$ in a humidified atmosphere with $5 \% \mathrm{CO}_{2}$. For all experiments, cells were subcultured after treatment with trypsin $(2.5 \mathrm{~g} / \mathrm{L}$ trypsin $0.2 \mathrm{~g} / \mathrm{L}$ EDTA) and plated in 24 well plates at a density of $5 \times 10^{4}$ cells/well with $1 \mathrm{~mL}$ of DMEM. The culture media was changed every two days.

\subsection{Caco-2 Treatment}

In order to compare the cytotoxicity of $7 \mathrm{KC}$, triol, $\alpha$-epoxy $\mathrm{C}$ and $\beta$-epoxy $\mathrm{C}$, all cholesterol oxides were dissolved in ethanol and used at a final concentration of $120 \mu \mathrm{M}$ in DMEM (containing $0.66 \%(\mathrm{v} / \mathrm{v})$ ethanol. One $\mathrm{mL}$ of these solutions were added to cell cultures and incubated for different times (24, 48 and $72 \mathrm{~h})$.

\subsection{Assessment of Mitochondrial Functionality}

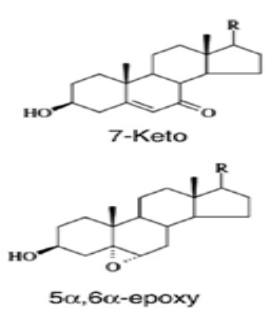

Mitochondrial functionality of the Caco-2 cells was assessed using the MTT assay[19]. This colorimetric method is based on the reduction of MTT tetrazolium ring by mitochondrial dehydrogenases[20], yielding a blue formazan product which is proportional to the number of viable cells and can be measured spectrophotometrically. After incubation with COPs, culture medium was removed and MTT solution $(0.5 \mathrm{mg} / \mathrm{mL}$ in PBS) was added to the cells, followed by incubation for $2 \mathrm{~h}$ at $37^{\circ} \mathrm{C} / 5 \% \mathrm{CO}_{2} / 95 \%$ humidity atmosphere. Then the medium was removed and the cells were harvested with $1.5 \mathrm{~mL}$ of a solution of 2-propanol $(0.1 \mathrm{~N} \mathrm{HCl}, 0.1 \% \mathrm{w} / \mathrm{v}$ Triton). The conversion to formazan was measured using a spectrophotometer at 570 $\mathrm{nm}$ with background subtraction at $690 \mathrm{~nm}$.

\subsection{Statistical Analysis}

Results are given as mean and standard deviations $(\mathrm{n}=$ 3-5). One-way analysis of variance (ANOVA) and LSD post-hoc test was used to determine differences in the cytotoxic effect between treatment and control. A significance level of $\mathrm{p}<0.05$ for all comparisons was adopted. Statgraphics Plus version 5.0 (Rockville, Maryland, USA) was used.

\section{Results}

In the present study, a comparison between the same compound at different times and different COPs at the same time was performed. From all the cholesterol oxides tested (see figure 1), it was found that triol was the most cytotoxic COP, with a percentage of cell viability ranged among 3.2 to 3.4 at all the times studied. The $7 \mathrm{KC}$ and $\beta$-epoxy $\mathrm{C}$ had similar percentages from 65.4 to 6.9 and 67.4 to 6.5 , respectively, during the time-period course; however, $7 \mathrm{KC}$ caused an earlier damaging effect to cells at $48 \mathrm{~h}$ compared with $\beta$-epoxy $C$ that evoked its highest cytotoxic effect at $72 \mathrm{~h}$. The $\alpha$-epoxy $\mathrm{C}$ was the compound that least affected cell viability ( 83.3 to $48.7 \%$ )(Figure 2). Thus, from a time-response standpoint the decreasing order of toxicity in Caco-2 cells exerted by these compounds was Triol $>7 \mathrm{KC}>$ $\beta$-epoxy $\mathrm{C}>\alpha$-epoxy C. Additionally, the morphological changes showing cell damage in Caco-2 cells treated with COPs at $120 \mu \mathrm{M}$ are illustrated in Figure 3.

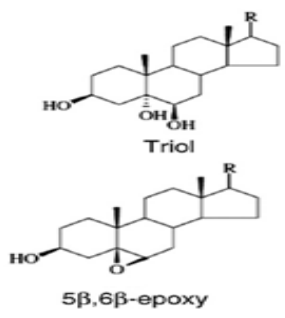

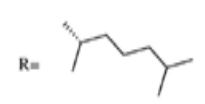

Figure 1. Structure of COPs tested on Caco-2 cells 


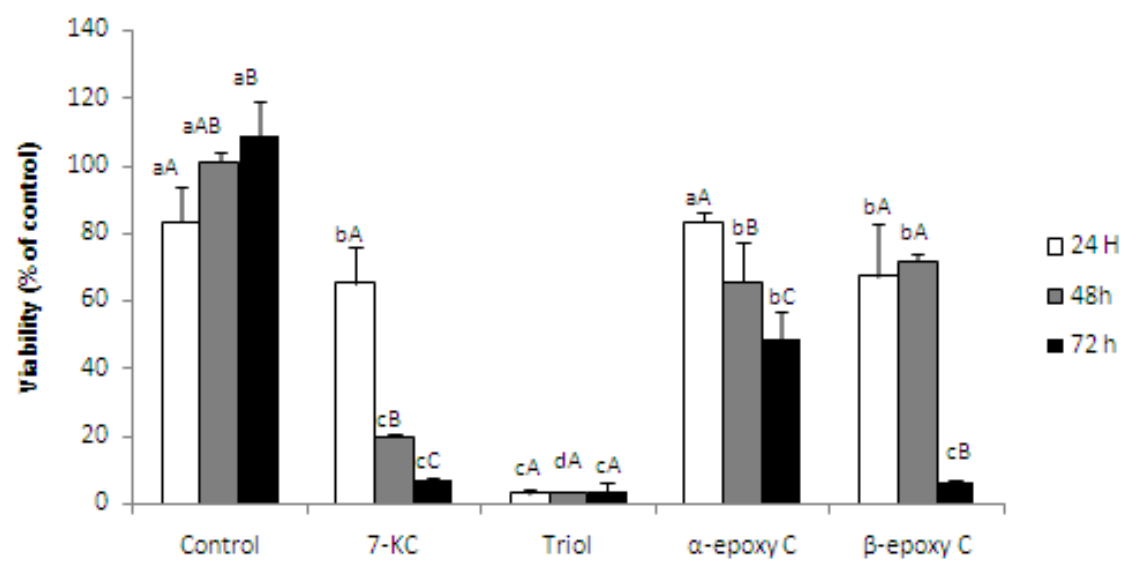

Figure 2. Cell viability determined as mitochondrial functionality by means MTT test in Caco-2 cells exposed to different COPs at $120 \mu \mathrm{M}$ during $24-72 \mathrm{~h}$. Distinct lowercase (differences among samples at the same time) or uppercase (differences in the same sample at different times) letters indicate statistically significant differences $(\mathrm{p}<0.05)$.

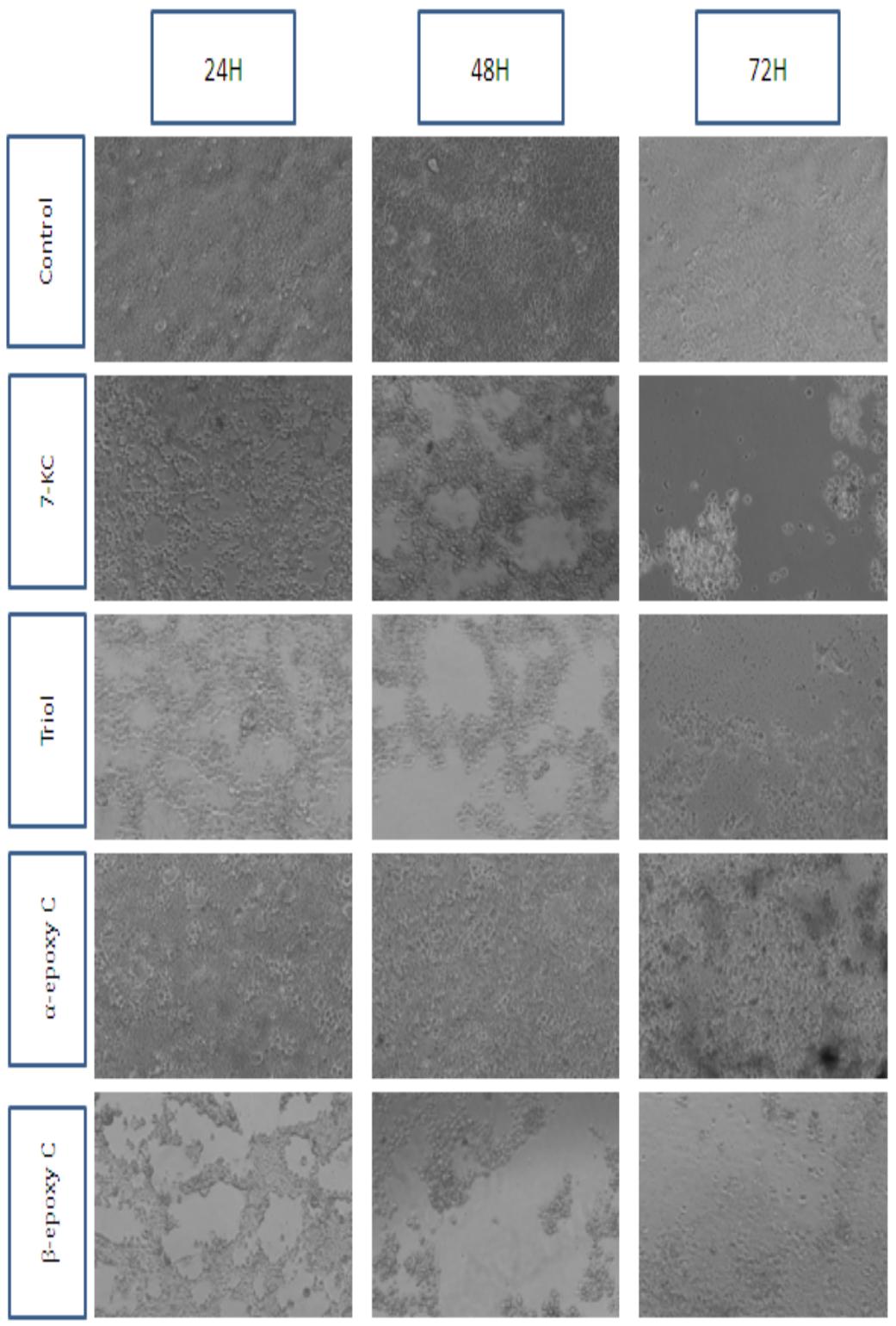

Figure 3. Morphological changes of Caco-2 cells showing the evolution of cellular damage caused by the various COPs tested at $120 \mu \mathrm{M}$ in the period of 24 to $72 \mathrm{~h}$, detected by light microscopic observation (10x original magnification). 


\section{Discussions}

The MTT assay showed a decrease in cell viability with increasing time of exposure to COPs. Decreased formazan formed in the MTT assay as an indicator of cell viability may reflect mitochondrial dysfunction, according to several studies, which have reported a role in inducing COPS altered mitochondrial integrity, reduced mitochondrial membrane potential and release of cytochrome c[21]. The results presented here suggest an induction of death in Caco-2 cells, probably via the mitochondrial pathway of apoptosis, although more studies are needed to confirm this assumption.

It is generally accepted that oxidized cholesterol and its derivatives are involved in the development of different vascular degeneration processes because of their pro-oxidant and pro-inflammatory properties[21,22]. These compounds are associated with an increased risk of developing colorectal cancer, although new lines of research indicate a potential activity against colon cancer[15]. Furthermore, in this sense, oxysterols (individually or in mixtures) have also been shown a promising beneficial activity against different cancer cell lines such as lung carcinoma A549, ovary adenocarcinoma SK-OV-3, skin melanoma SK-MEL-2, uterine sarcoma MES-SA and colon adenocarcinoma HCT-15[23], hepatocarcionoma HepG2, histiocytic lymphoma U937 and leukemia K562[24], C6 glioblastoma cells[25], and breast cancer MCF-7[26].

Excessive dietary intake of cholesterol, as well as oxidized lipids can sustain inflammatory and apoptotic reactions, reducing normal intestinal barrier function, and predispose the colon mucosa to colon cancer[27-29]. However, not all the COPs have the same cytotocity. COPs exert their damage in Caco-2 cells differently when administered separately. In this sense, a study of O'Sullivan et al.[17] showed that different COPs individually added to the undifferentiated Caco-2 cells in the range 0-62 $\mu \mathrm{M}$ cause a reduction in cell viability (measured with the neutral red uptake assay), following the order 25-OH-C $>\beta$-epoxy $\mathrm{C}=$ $7 \beta-\mathrm{OH}$-cholesterol $>\alpha$-epoxy $\mathrm{C}$ at $24 \mathrm{~h}$ of exposure, while $25-\mathrm{OH}-\mathrm{C}>7 \beta-\mathrm{OH}$-cholesterol $>\beta$-epoxy-C $>\alpha$-epoxy-C at $48 \mathrm{~h}$ of exposure. Cholesterol-5 $\beta 6 \beta$-epoxy was more cytotoxic than its isomer $\alpha$-epoxy $\mathrm{C}$ in the Caco- 2 cell line, which can be related to more efficient conversion of $\beta$-epoxy $\mathrm{C}$ to $5 \alpha$-cholestane-3 $\beta 6 \beta$-triol (triol), a compound that has proven to be a more effective inhibitor of HMG-CoA reductase than $\alpha$-or $\beta$-epoxycholesterol[17], which is one of the main mechanisms of action for its toxicity. In another similar study assessing the cytotoxicity of COPs in Caco-2 cells with MTT test, Biasi et al.[15] reported a significant $10 \%$ decrease in cell viability after $24 \mathrm{~h}$ exposure with a representative dietary mixture of oxysterols at $90 \mu \mathrm{M}$, containing 7KC (42.96\%), $\boldsymbol{\alpha}$-epoxy C (32.3\%), $\boldsymbol{\beta}$-epoxy C $(5.76 \%), \quad 7 \boldsymbol{\alpha}$-OH-cholesterol $\quad(4.26 \%) \quad$ and $7 \boldsymbol{\beta}$-OH-cholesterol (14.71\%). Likewise, Alemany et al.[14] reported a significant $\approx 15 \%$ of decrease in Caco- 2 cell viability after treatment with $7 \mathrm{KC}$ at $120 \mu \mathrm{M}$ for $24 \mathrm{~h}$.
Therefore, our results are in good agreement with previous works where COPs were tested to elucidate its toxicity in Caco- 2 cells.

As was discussed above, different cell populations can be more or less sensitive to the same concentration of COPs due, among others, to intrinsic factors such as enzymatic envelope (the interconversion from $\beta$ isomer to triol is greater in hepatocytes than in intestinal epithelial cells)[17]. But this it is not the only reason for the greater toxicity of triol. According to the $\mathrm{pH}$-cast theory, applied to the intestinal absorption of xenobiotics[30,31], the lipophilic compounds should pass better the epithelium through the transcellular pathway, but the triol, despite being more hydrophilic than the other COPs tested, exhibits greater cytotoxicity, as other authors who tested COPs reported[32]. Given this discrepancy between theory and practice, other explanatory theories as complementary deviations from the $\mathrm{pH}$-cast theory and bihiperbolic theory[31,33] suggest that not a greater lipophilic character means a greater absorption and pass to the bloodstream. Also and paradoxically is that, from a certain point, by increasing lipophilicity, bioavailability is reduced (both in magnitude and speed). The explanation for this effect is a functional layer between the lumen and the cell membrane, called diffusion layer[31].

\section{Conclusions}

As a summary of the results from the present study and considering other previous reports, it can be stated that Caco-2 cells are differently sensitive to cell death according to the distinct COPs assayed and exposure times, as MTT analysis confirmed. Triol was clearly the most cytotoxic compound, at all times of exposure, followed by $7 \mathrm{KC}$ and $\beta$ epoxy $\mathrm{C}$, being $\alpha$ - epoxy $\mathrm{C}$ the least toxic compound at any time assayed. This damage is related to the disruption of the integrity of mitochondrial function. Despite oxysterols are linked with different diseases (including colon cancer), paradoxically, their anticancer activity should not be ruled out, due to their selective action against colon cancer cells, as other authors have recently suggested. Thus, more studies in this direction are warranted to elucidate this potential beneficial activity against certain kinds of cancer.

\section{Acknowledgements}

This study was financially supported by the Spanish Ministry of Economy and Competitiveness through Project AGL 2012-39503-C02-01 (CICYT-FEDER).

\section{REFERENCES}

[1] A. Otaegui-Arrazola, M. Menéndez-Carreño, D. Ansorena, I. Astiasarán. Oxysterols: A world to explore. Food Chem. 
Toxicol. Vol.48, 3289-303, 2010.

[2] C.Y. Tai, Y.C. Chen, B.M. Chen. Analysis, formation and inhibition of cholesterol oxidation products in foods: an overview (part I). J. Food Drug Anal.Vol.7, 243-257, 1999.

[3] G. Cao, K.R. Bales, R.B. DeMattos, S. M. Paul. Liver X receptor mediated gene regulation and cholesterol homeostasis in brain: relevance to Alzheimer's disease therapeutics. Curr. Alzheimer Res, Vol.4, 179-184, 2007.

[4] K. Sathishkumar, S.N. Murthy, R.M. Uppu. Cytotoxic effects of oxysterols produced during ozonolysis of cholesterol in murine GT1-7 hypothalamic neurons. Free Radic. Res. Vol.41, 82-88, 2007.

[5] P. Jr. Wentworth, J. Nieva, C. Takeuchi, R. Galve, A. D. Wentworth, R. B. Dilley. Evidence for ozone formation in human atherosclerotic arteries. Science, Vol.302, 1053-1056, 2003.

[6] Q. Zhou, E. Wasowicz, B. Handler, L. Fleischer, F.A. Kummerow. An excess concentration of oxysterols in the plasma is cytotoxic to cultured endothelial cells. Atherosclerosis, Vol. 149, 191-197, 2000.

[7] S. Ramasamy, G.A. Boissonneault, B. Hennig. Oxysterol induced endothelial cell dysfunction in culture. J. Am. Coll. Nutr. Vol.1, 532-538, 1992.

[8] S. Roussi, F. Gosse, D. Aoude-Werner, X. Zhang., P. Geoffroy, M. Miesch, E. Marchioni, F. Raul. Perturbation of polyamine metabolism and its relation to cell death in human colon cancer cells treated by 7b-hydroxycholesterol and 7b-hydroxysitosterol. Int. J. Oncol. Vol.29, 1549-1554, 2006.

[9] S. Roussi, F. Gosse, D. Aoude-Werner, X. Zhang, P. Geoffroy, M. Miesch, E. Marchioni, F. Raul. Mitochondrial perturbation, oxidative stress and lysosomal destabilization are involved in 7b-hydroxysitosterol and 7b-hydroxycholesterol triggered apoptosis in human colon cancer cells. Apoptosis, Vol.12, 87-96, 2007.

[10] B. Sottero, P. Gamba, S. Gargiulo, G. Leonarduzzi, G. Poli. Cholesterol oxidation products and disease: an emerging topic of interest in medicinal chemistry, Curr. Med. Chem. Vol.16, 685-705, 2009.

[11] S. Lemaire-Ewing, C. Prunet, T. Montange, A. Vejux, A. Berthier, G. Bessède, L. Corcos, P. Gambert, D. Néel, G. Lizard. Comparison of the cytotoxic, pro-oxidant and pro-inflammatory characteristics of different oxysterols, Cell. Biol. Toxicol. Vol.21, 97-114, 2005.

[12] A. Vejux, L. Malvitte, G. Lizard. Side effects of oxysterols: cytotoxicity, oxidation, inflammation, and phospholipidosis. Braz. J. Med. Biol. Res., Vol.41, 545-56, 2008.

[13] G. García-Llatas, M.T. Rodríguez-Estrada. Current and new insights on phytosterol oxides in plant sterol-enriched food. Chem. Phys. Lipids, Vol.164, 607-24, 2011.

[14] L. Alemany, J.M. Laparra, R. Barberá, A. Alegría. Evaluation of the cytotoxic effect of 7keto-stigmasterol and 7 keto-cholesterol in human intestinal (Caco-2) cells. Food Chem. Toxicol., Vol.50, 3106-3113, 2012.

[15] F. Biasi, E. Chiarpotto, B. Sottero, M. Maina, C. Mascia, T. Guina, P. Gamba, S. Gargiulo, G. Testa, G. Leonarduzzi, G. Poli. Evidence of cell damage induced by major components of a diet-compatible mixture of oxysterols in human colon cancer Caco-2 cell line. Biochimie, Vol.95, 632-40, 2013.

[16] C. Mascia, M. Maina, E. Chiarpotto, G. Leonarduzzi, G. Poli, F. Biasi. Proinflammatory effect of cholesterol and its oxidation products on $\mathrm{CaCo}-2$ human enterocyte-like cells: effective protection by epigallocatechin-3-gallate. Free Radic. Biol. Med. 15, Vol.49, 2049-2057, 2010.

[17] A.J. O'Sullivan, Y.C. O'Callaghan, J.A. Woods, N.M. O'Brien. Toxicity of cholesterol oxidation products to Caco-2 and HepG2 cells: modulatory effects of alpha- and gamma-tocopherol. J Appl. Toxicol. Vol.23, 191-197, 2003.

[18] B. Romano, I. Fasolino, E. Pagano, R. Capasso, S. Pace, G. De Rosa, N. Milic, P. Orlando, A.A. Izzo, F. Borrelli. The chemopreventive action of bromelain, from pineapple stem (Ananascomosus L.), on colon carcinogenesis is related to antiproliferative and proapoptotic effects. Mol. Nutr. Food Res. Vol. 58, 457-465, 2014.

[19] A. Cilla, J.M. Laparra, A. Alegría, R. Barberá. Mineral and/or milk supplementation of fruit beverages helps in the prevention of $\mathrm{H} 2 \mathrm{O} 2$-induced oxidative stress in Caco-2 cells. Nutr. Hosp., Vol.26, 614-621, 2011.

[20] C. Ekmekcioglu, G. Strauss-Blasche, V.J. Leibetseder. Toxicological and biochemical effects of different beverages on human intestinal cells. Food Res. Int. Vol.32, 421-427, 1999.

[21] G.J. Schroepfer. Oxysterols: modulators of cholesterol metabolism and other processes. Physiol. Rev, Vol.80, 361-554, 2000.

[22] J.L. Yecies, H.H. Zhang, S. Menon, S. Liu, D. Yecies, A.I. Lipovsky. Akt stimulates hepatic SREBP1c and lipogenesis through parallel mTORC1-dependent and independent pathways. Cell Metab., Vol.14, 21-32, 2011.

[23] E.M. Roh, Q. Jin, H.G. Jin, J.E. Shin, E.J. Choi, Y.H. Moon, E.R. Woo. Structural implication in cytotoxic effects of sterols from Selaginella tamariscina. Arch. Pharm. Res. Vol.33, 1347-1353, 2010.

[24] J.W. Hyun, V. Holl, D. Weltin, P. Dufour, B. Luu, P. Bischoff. Effects of combinations of 7beta-hydroxycholesterol and anticancer drugs or ionizing radiation on the proliferation of cultured tumor cells. Anticancer Res. Vol.22, 943-948, 2002.

[25] J. de Waille, C. Fabre, C. Gaven, N. Bakalara. Similar pyruvate kinase modifications in glioblastoma cells by 7- $\beta$-hydroxycholesterol and glutamine withdrawal. Biochem. Pharmacol. Vol.86, 161-167, 2013.

[26] G. Segala, P. de Medina, L. Iuliano, C. Zerbinati, M.R. Paillasse, E. Noguer, F. Dalenc, B. Payré, V. C. Jordan, M. Record, S. Silvente-Poirot, M. Poirot. 5,6-Epoxy-cholesterols contribute to the anticancer pharmacology of tamoxifen in breast cancer cells. Biochem. Pharmacol. Vol.86, 175-89, 2013.

[27] T. Vihervaara, M. Jansen, R.L. Uronen, Y. Ohsaki, E. Ikonen, V.M. Olkkonen. Cytoplasmic oxysterol-binding proteins: sterol sensors or transporters? Chem. Phys. Lipids, Vol.164, 443-450, 2011.

[28] X. Wang, N.G. Zelenski, J. Yang, J. Sakai, M.S. Brown, J.L. Goldstein. Cleavage of sterol regulatory element binding proteins (SREBPs) by CPP32 during apoptosis. EMBO J., Vol.15, 1012-1020, 1996. 
[29] S. Lordan S, J.J. Mackrill, N.M. O’Brien. Oxysterols and mechanisms of apoptotic signaling: implications in the pathology of degenerative diseases. J. Nutr. Biochem., Vol.20, 321-336, 2009.

[30] C.A. Hogben, D.J. Tocco, B.B. Brodie, L.S. Schanker. On the mechanism of intestinal absorption of drugs. J. Pharmacol. Exp. Ther.Vol.125, 275-82, 1959.

[31] N.F.N. Ho, W.L. Higuchi.Theoretical model studies of drug absorption and transport in the GI Tract III. J. Pharm. Sci. Vol.61, 192-197, 1972.
[32] A. Meynier, A. Andre, J. Lherminier, A. Grandgirard, L. Demaison. Dietary oxysterols induce in vivo toxicity of coronary endothelial and smooth muscle cells. Eur. J. Nutr. Vol.44, 393-405, 2005.

[33] J.M. Plá-Delfina, J. Moreno. Intestinal absorption-partition relationships: a tentative functional nonlinear model. J. Pharmacokinet. Biopharm., Vol.9, 191-215, 1981. 